\title{
Fe/MgO POWDER COMPOSITE SINTERED BY MICROWAVE HEATING
}

\author{
R. Bureš ${ }^{1}$, M. Fáberová1, Z. Birčáková1, V. Koval'1, P. Kollár ${ }^{2}, J^{1}$. Füzer², M. Jakubčin², \\ P.Slovenský2
}
${ }^{1}$ Institute of Materials Research of Slovak Academy of Sciences, Watsonova 47, 04001 Košice, Slovak Republic
${ }^{2}$ Institute of Physics, Faculty of Science of P.J. Šafárik University, Park Angelinum 9, 04154
Košice, Slovak Republic
mfaberova@saske.sk

Keywords: microwave heating, powder sintering, metal-ceramics composite

\section{Introduction}

Composite materials based on ferromagnetic powder particles surrounded by electric insulation phase are known as soft magnetic composites (SMC). It is a group of 3D isotropic materials characterized by low coercivity, low energy losses at medium to higher frequencies and high resistivity [1]. SMC materials can contain organic, inorganic or hybrid electric insulation constituents [2]. Inorganic oxide ceramic compounds are suitable for SMC fabrication, because of their high temperature stability and high resistivity. Application of ceramic oxides is inseparable from limited ability to achieve high density of SMC's. Powder metallurgy (PM) technology is common way of SMC fabrication. The most simple and economic method is press and sintering technology. Residual porosity of PM materials depend on effectivity of densification process during pressing and sintering. In case of metallic powder materials it is possible to achieve high density already in the stage of cold pressing of powders. Short sintering is required to create tight bond among close packed powder particles. Hard and brittle ceramics is incompressible. Powder ceramic is consolidated using low pressure followed by long term sintering to achieve neck creation between ceramic powder particles. Metallic/ceramics coated powders are characterized by limited ability to plastic deformation in dependence on ceramic content and their volume distribution. Soft magnetic applications require to use thin and compact ceramic coating layer on the ferromagnetic particle [3]. This spatial distribution of the ceramic secondary phase have to be preserved during pressing and sintering technology steps to maximize magnetic properties [4]. Ideal SMC microstructure consists from the metallic primary phase and the regular ceramic network. Limited plastic deformation and requirement of well bonded ceramic network is the motivation to search new methods of SMC fabrication. One of perspective consolidation methods is the microwave sintering.

Study of the interaction mechanism of metal-ceramic composites during microwave sintering led to identification of so called micro-focusing effect. Densification of metalceramic during the microwave sintering is selective process induced by the mixed interaction mechanisms on the particle-free surface and interface as it was shown in Al-SiC powder composite [5]. Local focus effect of electromagnetic fields and its influence on microwave sintering of metal-ceramic composite was investigated in $\mathrm{Sn}-\mathrm{SiO}_{2}$ composite. This focus effect depends on the geometric configurations of particles, and may be an important factor for the microstructure evolution during microwave sintering. [6].

The SMC materials are hierarchic microstructurally inhomogeneous composites ordered to 3D continuous secondary-dielectric phase with isolated primary-ferromagnetic phase [7]. This ordering correspond to microstructurally inhomogeneous, but macroscopically 
homogeneous microstructures. Subject of the paper is an investigation of microwave sinterering behavior of the $\mathrm{Fe} / \mathrm{MgO}$ powder material as well as an influence of the microwave heating on soft magnetic and mechanical properties of the sintered composites.

\section{Material and methods}

Iron powder ASC100.29 (Höganäs, AB) with particle size distribution $\mathrm{d}_{0.1}=45 \mu \mathrm{m}, \mathrm{d}_{0.5}=100$ $\mu \mathrm{m}$ and $\mathrm{d}_{0.9}=195 \mu \mathrm{m}$ was used as ferromagnetic constituent. Electric insulation constituent was provided by $\mathrm{MgO}$ (US Research Nanomaterials, Inc.) with narrow particle size distribution $1 \mu \mathrm{m}$ of mean size. Powder mixtures were prepared using resonant acoustic mixing method in Resodyn ${ }^{\mathrm{TM}}$ LabRAM mixer. Hydraulic press machine LabTest $5.600 \mathrm{Zl}$ was used for cold pressing to prepare green body. Green compacts were sintered by conventional heating (CS) in chamber muffle furnace. Microwave (MW) sinterability analysis was realised in single mode microwave cavity at frequency of $2.45 \mathrm{GHz}$. Cylindrical cavity with dimensions in diameter of $28 \mathrm{~mm}$ and height of $80 \mathrm{~mm}$ was equipped with Impedance analyser HiPom and IR pyrometer Optris CT (supplied by UPV-Institute for Information and Communication Technologies). Microwave sintering was provided by multimode microwave laboratory system Hamilab V3000 (Synotherm) equipped with Raytek IR pyrometer. Density was measured by Archimedes method. Hardness measurement was provided by Vickers hardness tester Leco LM700AT. Elastic properties were measured by impulse excitation technique using Buzz-o-Sonic system. Resistivity was measured by four point probe method using Mitsubishi Loresta AX equipment. Complex permitivity and permeability were measured by impedance spectroscopy method using HP 4294A impedance analyser. Coercive force meter DX-320 was used for coercive force measurement. Transverse rupture strength was measured by three point bending test method using universal testing machine LabTest $5.600 \mathrm{Zl}$.

\section{Results and discussion}

Iron and magnesia oxide powder were dry mixed for 1 minute in LabRAM mixer to prepare $\mathrm{Fe}+2$ wt. $\% \mathrm{MgO}$ and $\mathrm{Fe}+5$ wt. $\% \mathrm{MgO}$ mixtures. Intensive acoustic mixing packed $\mathrm{Fe}$ and $\mathrm{MgO}$ in a micro-agglomerates as it is shown in Fig. 1. The mixtures were uniaxially cold pressed in closed die at pressing pressure $600 \mathrm{MPa}$ to the shape of cylinder size of $\phi 10 \times 3 \mathrm{~mm}$, prism bar size of $4 \times 5 \times 20 \mathrm{~mm}$ and ring shape size of $\phi_{\text {in }} 28 \times \phi_{\text {out }} 25 \times 3 \mathrm{~mm}$. Cylinder shape samples were sintered in the single mode MW cavity to investigate sinterability of the prepared mixtures. 


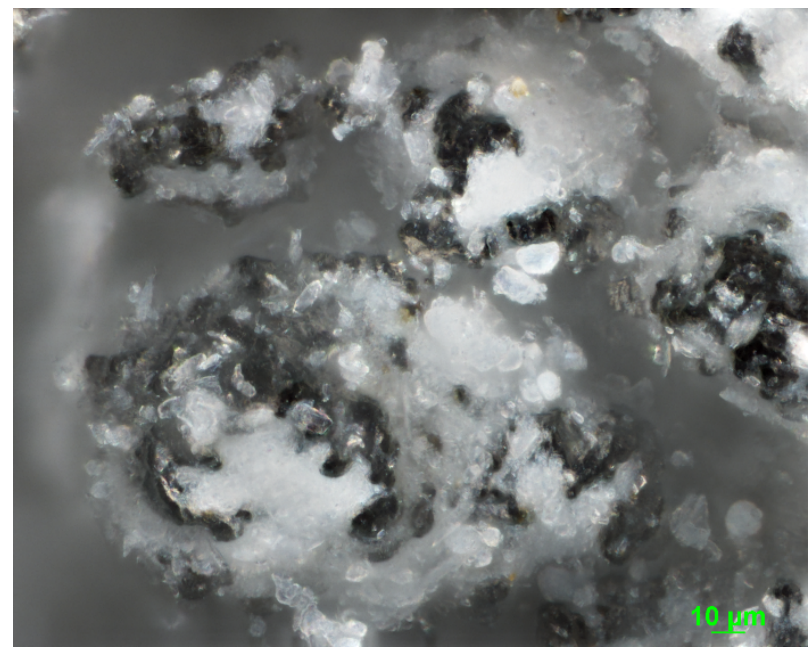

Fig. 1. $\mathrm{Fe}+5 \mathrm{wt} . \% \mathrm{MgO}$ dry mixed to micro-agglomerates.

In Figures 2-4 it is shown the time-temperature and MW energy absorption diagram of the single mode $\mathrm{MW}$ sintering process in air atmosphere at $600^{\circ} \mathrm{C}$. Pure iron green compact can be treated using MWS, whereas MW heating is more stable at lower relative density, Fig. 2. High density achieved at high pressing pressure $(900 \mathrm{MPa})$ leads to instability, plasma formation and thermal run away due to low resistivity at low porosity of the iron green compact. Pressing pressure has exactly the reverse effect on $\mathrm{MgO}$ heating as it is shown in Fig. 3. It was achieved limited temperature in MWS of low density $\mathrm{MgO}$ pressed at pressure of 100 and $300 \mathrm{MPa}$. $\mathrm{MgO}$ green compact pressed at $600 \mathrm{MPa}$ was possible to heat in $\mathrm{MW}$ to $600^{\circ} \mathrm{C}$. It can be expected that higher pressing pressure can improve stability of MW heating, but it is impossible to apply higher pressure due to spring back effect in pure $\mathrm{MgO}$ ceramic powder system. $\mathrm{Fe} / \mathrm{MgO}$ green compacts were pressed at $600 \mathrm{MPa}$ of pressing pressure. Results of SM MWS in Fig. 4 shows very good stable MW heating in case of $\mathrm{Fe} / 2 \mathrm{MgO}$ material. $\mathrm{Fe} / 5 \mathrm{MgO}$ can be controlled heated in $\mathrm{MW}$ with a little higher temperature deviation in comparison with $\mathrm{Fe} / 2 \mathrm{MgO}$. The results of complex dielectric permittivity analysis are presented in Table 1. Imaginary part of complex permittivity is increasing with electric conductivity of the interphase regions in powder system based on conductive metallic particles with insulation layer. Depending on the value of the $\varepsilon " 16400$ or 7800 for $\mathrm{Fe} / 2 \mathrm{MgO}$ and $\mathrm{Fe} / 5 \mathrm{MgO}$ respectively, the power absorbed in the interphases can be comparable to the power absorbed in the metal particles. The boundary losses act to smoothen the resonant absorption peaks, making it possible to implement stable microwave heating processes as it was demonstrated by simulation within semi-analytic model [8]. 


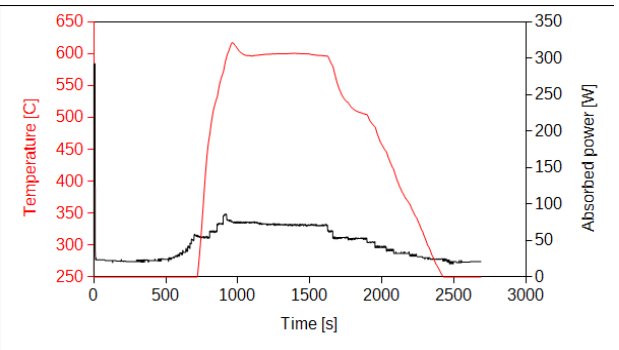

Fe green - $300 \mathrm{MPa}$

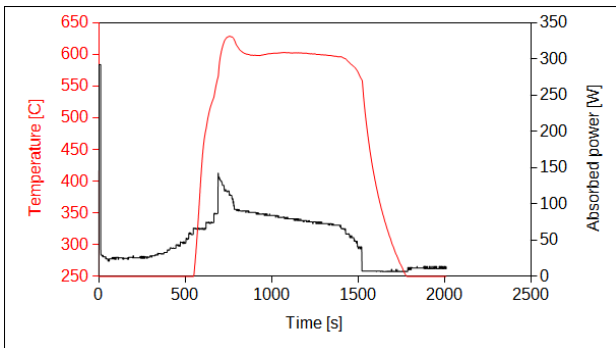

Fe green - $600 \mathrm{MPa}$

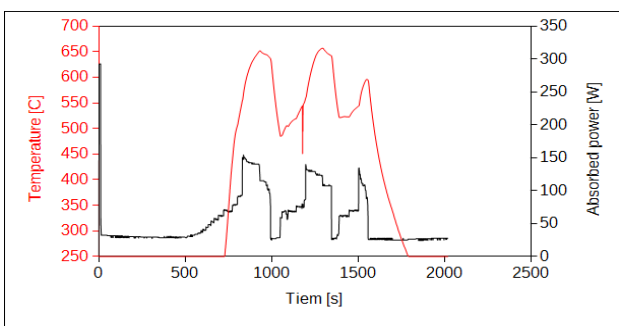

Fe green - $900 \mathrm{MPa}$

Fig. 2. Single mode microwave sintering analysis - Fe green compacts.

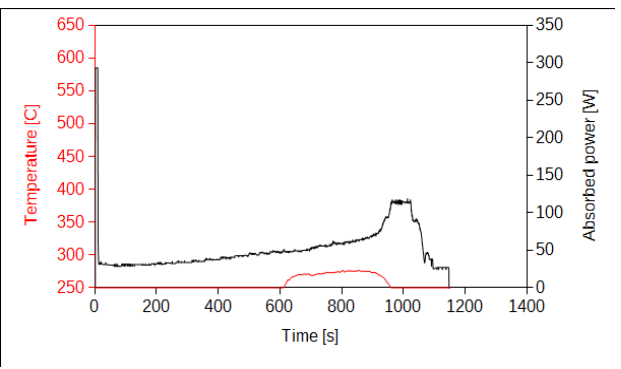

$\mathrm{MgO}$ green - $100 \mathrm{MPa}$

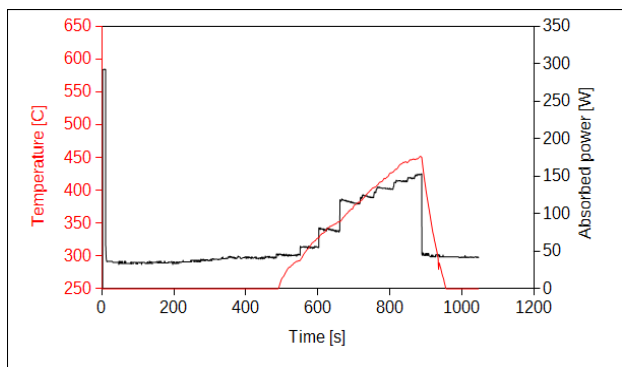

$\mathrm{MgO}$ green - $300 \mathrm{MPa}$

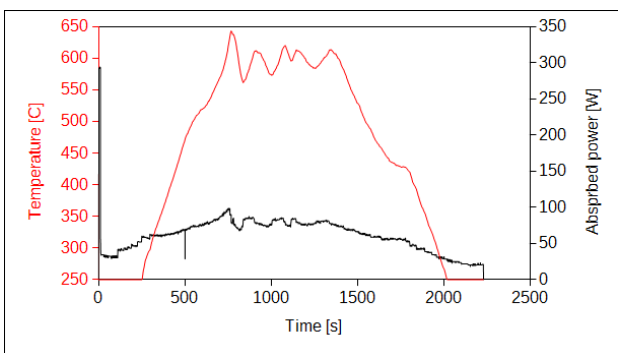

$$
\mathrm{MgO} \text { green }-600 \mathrm{MPa}
$$

Fig. 3. Single mode microwave sintering analysis $-\mathrm{MgO}$ green compacts. 


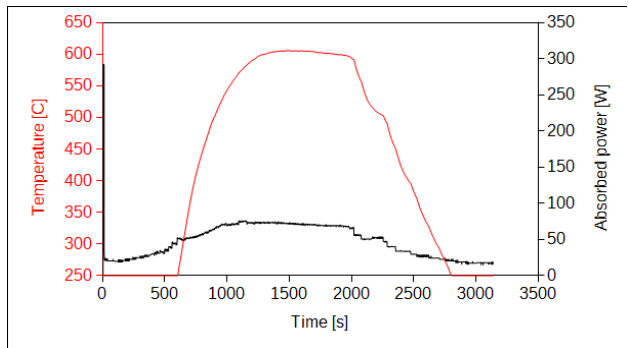

$\mathrm{Fe} / 2 \mathrm{MgO}$ green

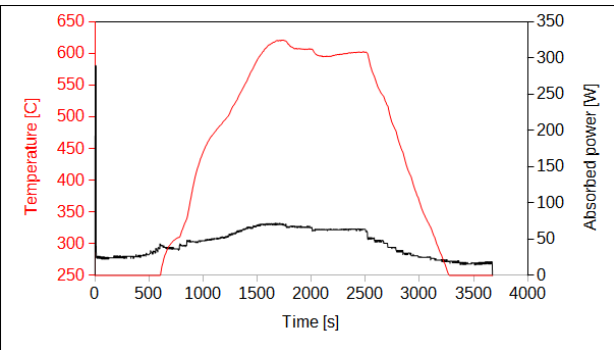

$\mathrm{Fe} / 5 \mathrm{MgO}$ green

Fig. 4. Single mode microwave sintering analysis $-\mathrm{Fe} / \mathrm{xMgO}$ green compacts.

Table 1. Dielectric properties of $\mathrm{Fe} / \mathrm{xMgO}$ green compacts.

\begin{tabular}{ccccc}
\hline sample & $\varepsilon^{\prime} @ 1 \mathrm{MHz}$ & $\varepsilon^{\prime \prime} @ 1 \mathrm{MHz}$ & $\varepsilon^{\prime} @ 10 \mathrm{MHz}$ & $\varepsilon^{\prime \prime} @ 10 \mathrm{MHz}$ \\
& {$[-]$} & {$[-]$} & {$[-]$} & {$[-]$} \\
\hline Fe-green & 23 & 5244 & 33 & 561 \\
MgO-green & 1.53 & 0.43 & 1 & 0.3 \\
Fe2MgO-green & 16 & 16400 & 6 & 1500 \\
Fe5MgO-green & 10 & 7800 & 4.8 & 816 \\
\hline
\end{tabular}

$\varepsilon^{\prime}$-Real part of complex permitivity, $\varepsilon^{\prime \prime}-$ Imaginary part of complex permitivity at specific frequency

On the basis of the MW sinterability evaluation the multimode MW sintering process was set. One sintering batch consisted from 3 cylinders, 3 prism bars and 3 rings of $\mathrm{Fe} / \mathrm{MgO}$ green samples. Experimental batch of samples was placed into the dense alumina crucible, then into the second low density alumina chamber and finally into the third alumina fiber chamber. Chambers and crucible were covered by top with the slot for pyrometric temperature measurement. This gradient density alumina assembly was closed in the double wall stainless steel water cooled multimode cylindrical microwave process chamber, in Fig. 5 , powered by $3 \times 1 \mathrm{~kW}$ magnetrons. MW output power was automatically driven based on temperature measurement feedback to the required temperature. Smooth process control was achieved by programmed corrections in the temperature regions where a change of MW energy absorption was predicted by the single mode MW analysis. Two composites $\mathrm{Fe} / 2 \mathrm{MgO}(\mathrm{M} 2)$ and $\mathrm{Fe} / 5 \mathrm{MgO}(\mathrm{M} 5)$ prepared using multimode $\mathrm{MWS}$ at $600^{\circ} \mathrm{C}$, for $15 \mathrm{~min}$., with $10^{\circ} \mathrm{C} / \mathrm{min}$ of heating and cooling rate, in dry air atmosphere. Analogous conventional sintered samples $\mathrm{C} 2$ and $\mathrm{C} 5$ were prepared using muffle furnace at $600^{\circ} \mathrm{C}$, for $60 \mathrm{~min}$., with $10^{\circ} \mathrm{C} / \mathrm{min}$ of heating and cooling rate, in air. 


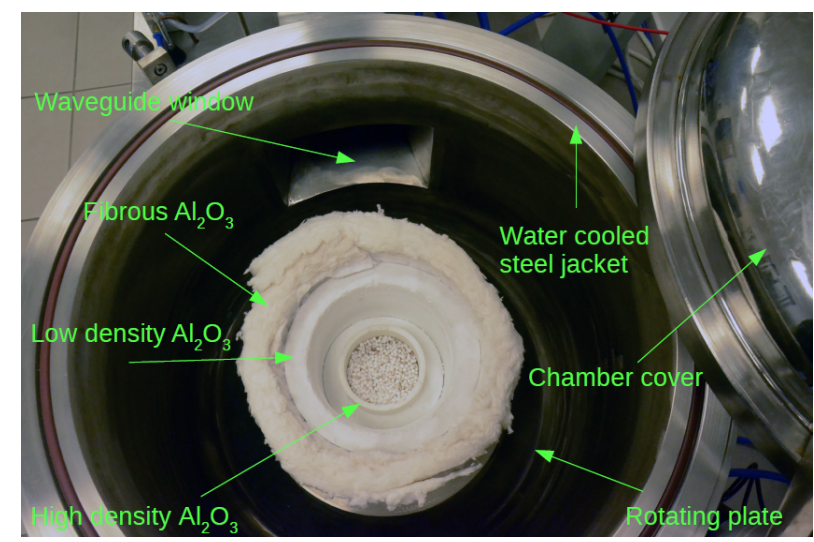

Fig. 5. Multimode microwave process chamber assembling.

Microwave sintering led to higher relative sintered density in comparison with conventional sintering as it is shown in Table 2. Elastic properties represented by Young modulus values are in good agreement with relative density. Flexural strength of $\mathrm{Fe} / 2 \mathrm{MgO}$ composite shows increasing value after MWS as well as statistical scatter is also higher in comparison with $\mathrm{C} 2$ sample. In case of MWS $\mathrm{Fe} / 5 \mathrm{MgO}$ composite, TRS value is lower with high value of statistical scatter than C5 sample. Results of the microhardness measurement indicates a reason of mechanical strength behavior. Two families of the microhardness values were found in the the case of $\mathrm{MW}$ sintered $\mathrm{Fe} / 5 \mathrm{MgO}$ composite. The value of $4.1 \mathrm{GPa}$ fit the tendency to decreasing microhardness value after MWS. Another significantly different value of $0.9 \mathrm{GPa}$ of MWS $\mathrm{Fe} / 5 \mathrm{MgO}$ composite indicate new phase creation in the microwave sintered composite at higher content of $\mathrm{MgO}$.

The results of electric and magnetic properties in dependence on sintering process technology are presented in Table 3 . The value of DC resistivity of the $\mathrm{Fe} / 2 \mathrm{MgO}$ composite is almost not influenced with sintering technology. It is not a case of $\mathrm{Fe} / 5 \mathrm{MgO}$ composite, which resistivity is decreasing by microwave sintering. Real part of the complex permeability at higher frequency $(1 \mathrm{MHz})$ has the same tendency as TRS value. MWS increases the real part of permeability value in comparison with CS with the exception of $\mathrm{Fe} / 5 \mathrm{MgO}$ composite. Real part of the complex permeability at lower frequency $(1 \mathrm{kHz})$ is increased by MWS. MWS causes increasing of coercive force values in both M2 and M5 composites. 
Table 2. Mechanical properties of the sintered composites.

\begin{tabular}{ccccc}
\hline sample & $\begin{array}{c}\mathrm{D}_{\mathrm{r}} \\
{[\%]}\end{array}$ & $\begin{array}{c}\mathrm{HV} 10 \\
{[\mathrm{GPa}]}\end{array}$ & $\begin{array}{c}\mathrm{E} \\
{[\mathrm{GPa}]}\end{array}$ & $\begin{array}{c}\text { TRS } \\
{[\mathrm{MPa}]}\end{array}$ \\
\hline $\mathrm{C} 2$ & 82.92 & 4.94 & 122.4 & 103.9 \\
& \pm 0.23 & & \pm 0.8 & \pm 2.2 \\
$\mathrm{C} 5$ & 80.82 & 5.71 & 92.0 & 77.9 \\
& \pm 0.71 & & \pm 2.8 & \pm 5.0 \\
\hline M2 & 84.88 & 3.64 & 133.2 & 109.4 \\
& \pm 0.66 & & \pm 4.7 & \pm 17.0 \\
M5 & 82.27 & $4.1 ; 0.9^{*}$ & 93.8 & 71.7 \\
& \pm 0.80 & & \pm 12.8 & \pm 21.0 \\
\hline
\end{tabular}

$\mathrm{D}_{\mathrm{r}}-$ Relative density, HV-Vickers hardness, E-Young modulus, TRS-Transverse Rupture Strength, "two groups of the hardness values were found

Table 3. Electric and magnetic properties of the sintered composites.

\begin{tabular}{|c|c|c|c|c|}
\hline sample & $\begin{array}{c}\rho \\
{[\Omega . \mathrm{cm}]}\end{array}$ & $\begin{array}{c}\mathrm{H}_{\mathrm{c}} \\
{[\mathrm{A} / \mathrm{m}]}\end{array}$ & $\begin{array}{c}\mu^{\prime} @ 1 \mathrm{kHz} \\
{[-]}\end{array}$ & $\begin{array}{c}\mu^{\prime} @ 1 \mathrm{MHz} \\
{[-]}\end{array}$ \\
\hline $\mathrm{C} 2$ & $\begin{array}{c}4.56 \mathrm{e}-4 \\
\pm 3.53 \mathrm{e}-5\end{array}$ & $\begin{array}{c}304.7 \\
\pm 7.7\end{array}$ & 55 & 10 \\
\hline $\mathrm{C} 5$ & $\begin{array}{c}5.24 \mathrm{e}-2 \\
\pm 6.47 \mathrm{e}-3\end{array}$ & $\begin{array}{c}321.5 \\
\pm 8.7\end{array}$ & 27 & 24 \\
\hline M2 & $\begin{array}{c}4.71 \mathrm{e}-4 \\
\pm 2.53 \mathrm{e}-5\end{array}$ & $\begin{array}{c}426.5 \\
\pm 7.0\end{array}$ & 71 & 12 \\
\hline M5 & $\begin{array}{c}6.39 \mathrm{e}-3 \\
\pm 5.23 \mathrm{e}-4\end{array}$ & $\begin{array}{l}575.2 \\
\pm 9.2\end{array}$ & 40 & 21 \\
\hline
\end{tabular}

$\rho$-Resistivity, $\mathrm{H}_{\mathrm{c}}-$ Coercive force at $30 \mathrm{kA} / \mathrm{m}, \mu^{\prime}-$ Real part of complex permeability at specific frequency

Results of the complex permittivity measurements in Table 4 show a tendency in dielectric properties in dependence on heating technology. Real part of complex permittivity is increased by MWS as well as imaginary part of complex permittivity is decreased at the same time in case of $\mathrm{Fe} / 2 \mathrm{MgO}$ composite. Different behavior were found in case of $\mathrm{Fe} / 5 \mathrm{MgO}$ composite. Real part of complex permittivity of the M5 is significantly lower in comparison with CS composites, while the imaginary part of complex permittivity is very little influenced by a heating technology.

Table 4. Dielectric properties of Fe/xMgO sintered composites.

\begin{tabular}{ccccc}
\hline sample & $\varepsilon^{\prime} @ 1 \mathrm{MHz}$ & $\varepsilon^{\prime \prime} @ 1 \mathrm{MHz}$ & $\varepsilon^{\prime} @ 10 \mathrm{MHz}$ & $\varepsilon^{\prime \prime} @ 10 \mathrm{MHz}$ \\
& {$[-]$} & {$[-]$} & {$[-]$} & {$[-]$} \\
\hline C2 & 1.6 & 4800 & 5 & 710 \\
C5 & 14 & 1050 & 14 & 109.2 \\
\hline M2 & 2 & 2400 & 6.4 & 480 \\
M5 & 4 & 1040 & 4.8 & 100.8 \\
\hline
\end{tabular}

$\varepsilon^{\prime}-$ Real part of complex permitivity, $\varepsilon^{\prime \prime}$-Imaginary part of complex permitivity at specific frequency 
Light optical microscopy observation of the sintered composites is presented in Fig. 6 . Lower content of the $\mathrm{MgO}$ in $\mathrm{Fe} 2 \mathrm{MgO}$ powder material leads to relatively regular spatial distribution of the $\mathrm{MgO}$ in sintered composite. Increasing $\mathrm{MgO}$ content causes higher tendency to agglomeration of the secondary phase. MWS process helped to preserve distribution of $\mathrm{MgO}$ and suppress formation of iron-iron connections in $\mathrm{Fe} 2 \mathrm{MgO}$ composite. In case of $\mathrm{Fe} 5 \mathrm{MgO}$ composite, strong agglomeration process were supported by MWS. Microstructure observations confirm partial formation of a new phase in the interphase structure region between $\mathrm{Fe}$ and $\mathrm{MgO}$ in $\mathrm{MWS} \mathrm{Fe} 5 \mathrm{MgO}$ composites. Non-stoichiometric $\mathrm{MgFe}_{2} \mathrm{O}_{4}$ formation can be expected in connection of $\mathrm{MgO}$ with Fe particles [9], because iron particles contained residual oxides as well as sintering process was done in air atmosphere.

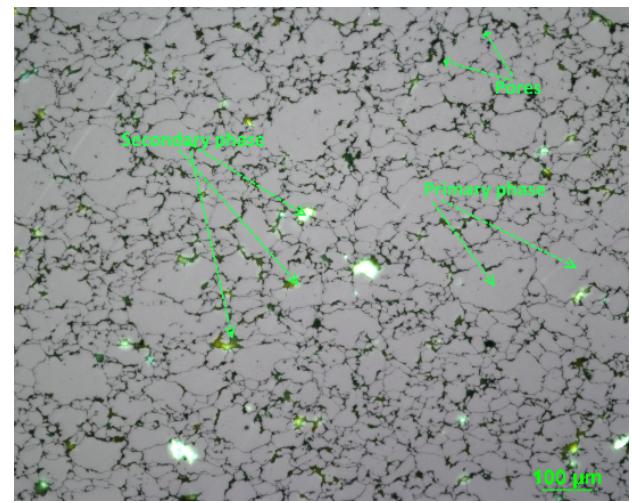

$\mathrm{Fe} / 2 \mathrm{MgO}-\mathrm{CS}$

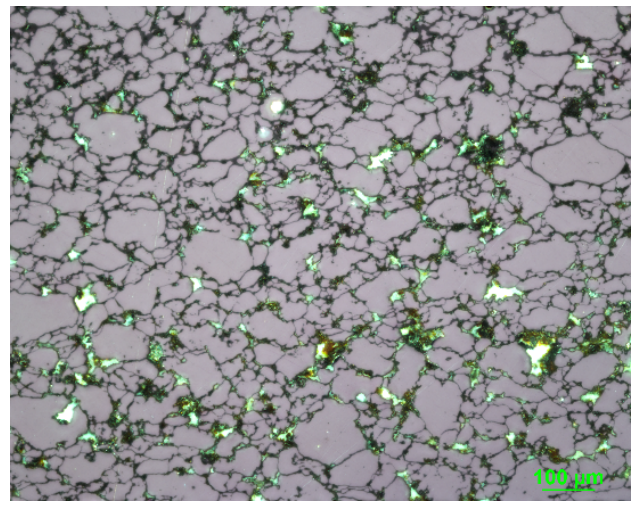

$\mathrm{Fe} / 5 \mathrm{MgO}-\mathrm{CS}$

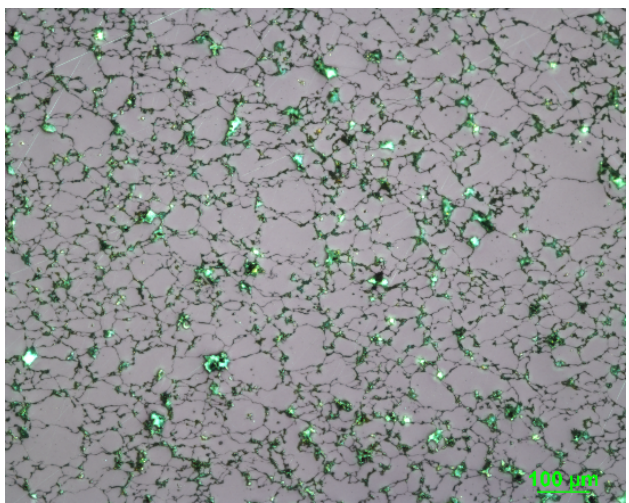

$\mathrm{Fe} / 2 \mathrm{MgO}-\mathrm{MW}$

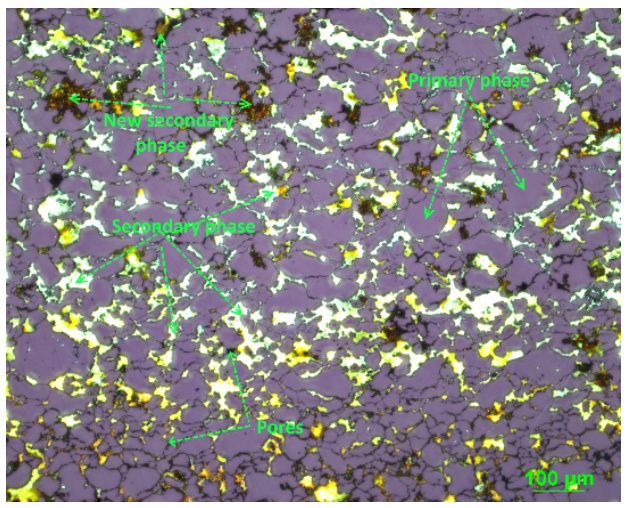

$\mathrm{Fe} / 5 \mathrm{MgO}-\mathrm{MW}$

Fig. 6. Microstructure of microwave and conventionally sintered composites observed in polarised light by light optical microscopy.

There is a focus effect of microwave E-fields between the metallic-ceramic particles. For example, the peak microwave E-field within the neck region between the ceramic and metallic particles is about 24.8 times of the applied field as it was shown Y.C. Li [5,6]. This effect will accelerate the mass diffusion and promote the sintering process, and may be an important mechanism for new phase creation or it can create specific distribution of 
secondary phase in the composite matrix. This behaviour can be supported or suppressed by small changes in content ratio of the dielectric constituent in the composite. Yoshikawa present recent studies and introduced some topics on negative permittivity of metallic materials and some specific phenomena related with the so-called "microwave non-thermal effect" [10]. This can be a way to clarify different properties of the FeMgO composites achieved in microwave sintering and conventional sintering process.

\section{Conclusions}

Powder soft magnetic composites $\mathrm{Fe} / 2 \mathrm{MgO}$ and $\mathrm{Fe} / 5 \mathrm{MgO}$ were prepared using press and sintering method. Sinterability of Fe-MgO powder system was investigated using single mode microwave sintering and complex permittivity measurement. Mechanical, elastic, electric and magnetic properties of microwave sintered composites were investigated. FeMgO SMC material can be effectively produced using microwave sintering process. Sintered composites differ in physical and mechanical properties in dependence on applied sintering technology as well as in dependence on $\mathrm{MgO}$ content ratio. Microwave sintering technology led to different microstructure formation in $\mathrm{Fe} / 5 \mathrm{MgO}$ composite.

\section{Acknowledgement}

This work was supported by projects: APVV 0115-15 and VEGA 2/0108/18.

\section{References}

[1] Périgo, E.A., Weidenfeller, B., Kollár, P., Füzer, J., Appl. Phys. Rev., 2018, 5, 031301-1-37

[2] Bures, R., Strečková, M., Fáberová, M., Kollár, P., Füzer, J., Arch. Metall. Mater., 2017, 62 (2B), 1149-1154

[3] Bures, R., Fáberová, M., Kurek, P., PMP, 2018, 18, 103-110

[4] Pittini-Yamada, Y., Périgo, E.A., de Hazan, Y., Nakahara, S., Acta Mater., 2011, 59, 4291-4302

[5] Li, Y.C., Xu, F., Hu, X.F., Kang, D., Xiao, T.Q., Wu, X.P., Acta Mater., 2014, 66, 293-301

[6] Li, Y., Xu, F., Luan, Y., Yan, X., Dong, B., Shen, Y., Hu, X., J. Alloys Compd., 2016, 687, 943-953

[7] Huang, L.J., Geng, L., Peng, H-X., Prog. Mater. Sci., 2015, 71, 93-168

[8] Rybakov, K.I., Volkovskaya, I.I., Ceram. Int., 2019, 45, 9567-9572

[9] Deraz, N.M., Abd-Elkader, O.H., Int. J. Electrochem. Sci., 2013, 8, 8632-8644

[10] Yoshikawa, N., IOP Conf. Ser.: Mater. Sci. Eng., 2018, 424, 012041-4 